\title{
Moderate hyperoxic versus near- physiological oxygen targets during and after coronary artery bypass surgery: a randomised controlled trial
}

Bob Smit ${ }^{1 *}$ (D) Yvo M. Smulders², Monique C. de Waard ${ }^{1}$, Christa Boer ${ }^{3}$, Alexander B. A. Vonk ${ }^{4}$, Dennis Veerhoek ${ }^{4}$, Suzanne Kamminga ${ }^{3}$, Harm-Jan S. de Grooth', Juan J. García-Vallejo ${ }^{5}$, Rene J. P. Musters ${ }^{6}$, Armand R. J. Girbes ${ }^{1}$, Heleen M. Oudemans - van Straaten ${ }^{1}$ and Angelique M. E. Spoelstra - de Man ${ }^{1}$

\begin{abstract}
Background: The safety of perioperative hyperoxia is currently unclear. Previous studies in patients undergoing coronary artery bypass surgery suggest reduced myocardial damage when avoiding extreme perioperative hyperoxia $(>400 \mathrm{mmHg}$ ). In this study we investigated whether an oxygenation strategy from moderate hyperoxia to a near-physiological oxygen tension reduces myocardial damage and improves haemodynamics, organ dysfunction and oxidative stress.

Methods: This was a single-blind, single-centre, open-label, randomised controlled trial in patients undergoing elective coronary artery bypass surgery. Fifty patients were randomised to a partial pressure of oxygen in arterial blood $\left(\mathrm{P}_{\mathrm{a}} \mathrm{O}_{2}\right)$ target of $200-220 \mathrm{mmHg}$ during cardiopulmonary bypass and $130-150 \mathrm{mmHg}$ during intensive care unit (ICU) admission (control group) versus lower targets of 130-150 mmHg during cardiopulmonary bypass and 80-100 mmHg at the ICU (conservative group). Primary outcome was myocardial injury (CK-MB and Troponin-T) at ICU admission and 2, 6 and 12 hours thereafter.

Results: Weighted $\mathrm{P}_{\mathrm{a}} \mathrm{O}_{2}$ during cardiopulmonary bypass was $220 \mathrm{mmHg}$ (interquartile range (IQR) 211-233) vs. 157 (151-162) in the control and conservative group, respectively $(P<0.0001)$. During ICU admission, weighted $\mathrm{P}_{\mathrm{a}} \mathrm{O}_{2}$ was $107 \mathrm{mmHg}(86-141)$ vs. 90 (84-98) $(P=0.03)$, respectively. Area under the curve of CK-MB was median $23.5 \mu \mathrm{g} / \mathrm{L} / \mathrm{h}(\mathrm{IQR} 18.4-28.1)$ vs. $21.5(15.8-26.6)(P=0.35)$ and $0.30 \mu \mathrm{g} / \mathrm{L} / \mathrm{h}(0.25-0.44) \mathrm{vs} .0 .39(0.24-0.43)(P=0.81)$ for Troponin-T. Cardiac index, systemic vascular resistance index, creatinine, lactate and F2-isoprostane levels were not different between groups.
\end{abstract}

Conclusions: Compared to moderate hyperoxia, a near-physiological oxygen strategy does not reduce myocardial damage in patients undergoing coronary artery bypass surgery. Conservative oxygen administration was not associated with increased lactate levels or hypoxic events.

Trial registration: Netherlands Trial Registry NTR4375, registered on 30 January 2014

Keywords: Hyperoxia, Oxygen, Intensive care unit, Cardiac surgery, CABG

\footnotetext{
* Correspondence: b.smit@vumc.nl

${ }^{1}$ Department of Intensive Care, VU University Medical Center, Amsterdam,

The Netherlands

Full list of author information is available at the end of the article
} 


\section{Background}

During cardiac surgery, and especially during cardiopulmonary bypass $(\mathrm{CPB})$, patients often receive supplemental oxygen as a precaution to prevent hypoxia. As a result, the arterial oxygen tension (partial pressure of oxygen in arterial blood; $\mathrm{P}_{\mathrm{a}} \mathrm{O}_{2}$ ) often rises to supraphysiological levels (hyperoxia), which is by many considered as a salutary oxygen reserve. $\mathrm{P}_{\mathrm{a}} \mathrm{O}_{2}$ levels of more than 200 to $300 \mathrm{mmHg}$ during $\mathrm{CPB}$ are not exceptional [1-6] and hyperoxia is also common in mechanically ventilated patients in the intensive care unit (ICU) $[7,8]$. There are currently no guidelines on oxygenation during cardiac surgery. For intensive care, current target $\mathrm{P}_{\mathrm{a}} \mathrm{O}_{2}$ recommendations are limited to patients with acute respiratory distress syndrome [9].

The safety of hyperoxia is questionable $[10,11]$. Besides the direct toxic effect of high fractions of inspired oxygen on lung tissue, animal [12-14] and human studies [15-19] show that hyperoxia induces vasoconstriction and may reduce cardiac output and organ perfusion. The mechanism of hyperoxic vasoconstriction is unclear, but augmented production of reactive oxygen species (ROS) seems to play a pivotal role [20, 21]. Excessive ROS may, amongst other things, enhance ischaemia/reperfusion injury, which may translate into worse clinical outcome.

In patients after cardiac arrest, hyperoxia is associated with worse functional outcome and increased mortality [22-26]. In patients with cerebral [27] or myocardial infarction [28], hyperoxia has been shown to increase infarct size and mortality. Data on the effect of oxygen on cardiac markers are scarce, since in animal studies direct measurements of infarct size are preferred and human studies are lacking. However, the recently published AVOID trial shows increased Troponin-I and creatine kinase (CK) when patients received supplemental oxygen after myocardial infarction [28].

Patients undergoing coronary artery bypass graft (CABG) surgery may be particularly vulnerable to the effects of hyperoxia because of fluctuations in cardiac function due to anaesthesia, blood loss, altered temperature, non-pulsatile perfusion and fluid shifts post-surgery. Also, hyperoxia may have detrimental effects on CPB-related myocardial ischaemia/reperfusion injury, pulmonary reperfusion and systemic inflammation.

The few clinical trials addressing the effect of hyperoxia during or after CABG surgery $[1-6,29]$ suggest that avoidance of extreme hyperoxia reduces myocardial damage $(>400 \mathrm{mmHg})[1,2]$. The design of these studies is variable, with exposure of patients to single $[4,5]$ or multiple short episodes [6] of hyperoxia and application of different oxygen tensions during reperfusion [2] or continuously throughout $\mathrm{CPB}[1]$. In recognition of direct pulmonary toxic effects of high inspiratory oxygen fractions these extreme $\mathrm{P}_{\mathrm{a}} \mathrm{O}_{2}$ values $(\sim 400 \mathrm{mmHg})$ are no longer used in current practice. Nevertheless, currently employed oxygen levels remain high, which raises the question whether further $\mathrm{P}_{\mathrm{a}} \mathrm{O}_{2}$ reductions are beneficial. Additionally, no studies continued to control the arterial oxygen tension after admission to the ICU.

The aim of this randomised controlled trial (RCT) was to determine whether near-physiological oxygen targets during and after CABG surgery reduces myocardial damage and improves haemodynamics, organ function and oxidative stress compared to standard care, which involves moderate hyperoxia.

\section{Methods}

\section{Study design and ethical approval}

This investigator-initiated, single-centre, RCT (Netherlands Trial Register number NTR4375) was performed at the operating room (OR) and ICU of the VU University Medical Centre (Amsterdam, the Netherlands). The study protocol was approved by the Dutch Central Committee on Research Involving Human Subjects (NL43882.029.13).

\section{Patients}

Patients over 18 years of age with a body surface index $\geq 1.9 \mathrm{~m}^{2}$ and a preoperative haemoglobin concentration $\geq 121 \mathrm{~g} / \mathrm{L}$, scheduled for elective, isolated CABG surgery with CPB were approached for participation and included in the study after written informed consent. Body surface index and haemoglobin criteria were chosen to ensure sufficient oxygen-carrying capacity of blood after haemodiluton by the CPB circuit. Exclusion criteria were presence of a perioperative intra-aortic balloon pump or a medical history positive for chronic obstructive pulmonary disease.

\section{Clinical management Anaesthesia}

Anaesthesia was induced with a combination of sufentanil $(3-7 \mu \mathrm{g} / \mathrm{kg})$, midazolam $(0.1 \mathrm{mg} / \mathrm{kg})$ and pancuroniumbromide $(0.1 \mathrm{mg} / \mathrm{kg})$ or rocuronium $(0.6 \mathrm{mg} / \mathrm{kg})$. General anaesthesia was maintained using propofol (200-400 mg/h). After induction, all patients received dexamethasone (1 mg/kg), cefazoline (1000 mg) and tranexamic acid $(1000 \mathrm{mg})$. Another $2000 \mathrm{mg}$ of tranexamic acid was administered following termination of $\mathrm{CPB}$. After surgery, patients were supported with a low dose of dopamine.

\section{Cardiopulmonary bypass}

Non-pulsatile $\mathrm{CPB}$ was initiated in a standard fashion with moderate hypothermia $\left(34-36{ }^{\circ} \mathrm{C}\right)$. Depending on the operating surgeon, cardiac arrest was achieved by using $4{ }^{\circ} \mathrm{C}$ crystalloid cardioplegia solution or normothermic blood cardioplegia. After surgery, shed blood 
was washed, concentrated and returned to the patient. For more details, see Additional file 1.

\section{Intensive care unit}

Propofol sedation was stopped when haemodynamics were stable, chest drain production was minimal and patient temperature was normal. When sufficiently awake, patients were extubated. Patients received three gifts of cefazoline $(1000 \mathrm{mg})$ at 8 -h intervals.

\section{Randomisation and intervention}

After inclusion, patients were randomised by drawing of sealed envelopes into the "control" or "conservative" group (1:1 ratio). Patients were enrolled and assigned by $\mathrm{BS}$, who was not involved in the clinical care of patients. While on $\mathrm{CPB}$, the control group was oxygenated, aiming for a target $\mathrm{P}_{\mathrm{a}} \mathrm{O}_{2}$ of 200-220 mmHg during placement of the aortic cross-clamp as per current practice. After admission to the ICU, a target $\mathrm{P}_{\mathrm{a}} \mathrm{O}_{2}$ of 130-150 mmHg was applied. The conservative group was oxygenated to a target $\mathrm{P}_{\mathrm{a}} \mathrm{O}_{2}$ of $130-150 \mathrm{mmHg}$ during aortic cross-clamping and $80-100 \mathrm{mmHg}$ at the ICU. Surgeons were unaware of group allocation.

Patients in both study groups were pre-oxygenated with a fraction of inspired oxygen $\left(\mathrm{F}_{\mathrm{I}} \mathrm{O}_{2}\right)$ of 1.0 and subsequently intubated. In the control group, $\mathrm{F}_{\mathrm{I}} \mathrm{O}_{2}$ was set to a minimum of 0.4 and a maximum of 0.6 . In the conservative group, $\mathrm{F}_{\mathrm{I}} \mathrm{O}_{2}$ was set lower than or equal to 0.40 , while ensuring an oxygen saturation $\geq 94 \%$. During $\mathrm{CPB}, \mathrm{P}_{\mathrm{a}} \mathrm{O}_{2}$ was continuously monitored with a Terumo CDI 500 (Terumo Europe, Leuven, Belgium). After ICU admission, $\mathrm{P}_{\mathrm{a}} \mathrm{O}_{2}$ was monitored approximately every hour by blood gas sampling. While patients were intubated, $\mathrm{F}_{\mathrm{I}} \mathrm{O}_{2}$ was adjusted (with an upper limit of $60 \%$, higher only if clinically necessary) to reach target $\mathrm{P}_{\mathrm{a}} \mathrm{O}_{2}$. After extubation, patients breathed room air or received supplemental oxygen through a nasal cannula or an oxygen mask. Other means of non-mechanical ventilation were only issued on clinical indication and not for study purposes.

\section{Primary and secondary endpoints}

The primary endpoint was myocardial damage, as reflected by area under the curve (AUC) of CK-MB. Secondary endpoints were differences in haemodynamics, tissue perfusion, organ function, and oxidative stress. As safety outcomes, we monitored for desaturations (oxygen saturation $<88 \%)$ and hypoxic events $\left(\mathrm{P}_{\mathrm{a}} \mathrm{O}_{2}<55 \mathrm{mmHg}\right)$.

\section{Myocardial damage/tissue perfusion, organ function and injury}

Myocardial damage was determined by measuring CK$\mathrm{MB}$, Troponin-T and CK at the following time points: prior to induction of anaesthesia and 0, 2, 6 and $12 \mathrm{~h}$ after ICU admission. If no peak value was measured within this timeframe, additional measurements were performed at 6-h intervals. As an estimation of organ perfusion and oxygenation, creatinine and lactate levels were measured at the same time points. Lung injury score (LIS) was assessed at ICU admission and 2 days post-operatively [30]. $\mathrm{P}_{\mathrm{a}} \mathrm{O}_{2} / \mathrm{F}_{\mathrm{I}} \mathrm{O}_{2}$ ratio was measured approximately every hour, simultaneously with blood gas analyses for intervention control.

\section{Haemodynamics}

In patients who received a pulmonary artery catheter (under the anaesthesiologist's discretion), cardiac index (CI) and systemic vascular resistance index (SVRI) were measured prior to thoracotomy, after chest closure and $0,2,6$ and $12 \mathrm{~h}$ after ICU admission.

\section{Oxidative stress}

Lipid peroxidation by ROS was assessed by measuring F2-isoprostanes (8-iso prostaglandin F2 $\alpha$, iPF2 $\alpha$-III) in plasma by liquid chromatography tandem mass spectrometry. EDTA samples were obtained prior to induction of anaesthesia and $6 \mathrm{~h}$ after ICU admission. Directly after sampling, blood was centrifuged at $2500 \mathrm{~g}$ for 10 minutes and plasma was stored at $-80{ }^{\circ} \mathrm{C}$ until analysis.

For the measurement of ROS production by circulating polymorphonuclear leukocytes (PMN), samples were taken before induction of anaesthesia and at $1 \mathrm{~h}$ of $\mathrm{CPB}$. A portion of whole blood was incubated with a fluorescent ROS probe for $1 \mathrm{~h}$ (CellROX Green; Invitrogen, Grand Island, NY, USA). Mean fluorescence intensity (MFI) of 5000 cells, which is proportionate to the ROS produced, was then measured on a Beckton Dickinson FACS Calibur flowcytometer.

For a more elaborate description of these methods, see Additional file 2.

\section{Statistics/analysis \\ Sample size calculation}

A previous small trial, which compared extreme versus less extreme hyperoxia during $\mathrm{CPB}$, showed a perioperative increase in CK-MB of 20 to $80 \mu \mathrm{g} / \mathrm{L}$ and 20 to $45 \mu \mathrm{g} / \mathrm{L}$, respectively [2]. In the present trial, we expected the effect to be smaller. With an anticipated standard deviation of $20 \mu \mathrm{g} / \mathrm{L}$ and an $\alpha$ of 0.05 , inclusion of 25 patients in each arm provides a power of $80 \%$ to detect a CK-MB difference of $20 \%$.

\section{Analysis}

Data were analysed according to the intention-to-treat principle (ITT). Data are presented as median and interquartile range (IQR) unless otherwise stated. AUC was calculated using the Trapezoidal Rule. Time-weighted $\mathrm{P}_{\mathrm{a}} \mathrm{O}_{2}$ was calculated by multiplying the last $\mathrm{P}_{\mathrm{a}} \mathrm{O}_{2}$ of two consecutive measurements by the period of time 
between these measurements; the sum of all products was then divided by total time. Weighted $\mathrm{P}_{\mathrm{a}} \mathrm{O}_{2} / \mathrm{F}_{\mathrm{I}} \mathrm{O}_{2}$ ratios were calculated following the same principle. Differences between groups were tested with the nonparametric Mann-Whitney U test or Fisher's exact test where appropriate.

\section{Results}

Patients

In the period between November 2013 and May 2015, 57 patients gave written informed consent for study participation. Seven patients were excluded prior to the start of the study protocol due to changes in the surgery schedule. The remaining 50 patients, 25 in each arm, completed the study protocol and were included for ITT analysis. The participants were Caucasian males with a median age of 67 years (IQR 63-71). For more detailed baseline and surgical characteristics of patients, see Table 1. For a CONSORT flow diagram, see Additional file 3 .

\section{Intervention}

In the control group, weighted $\mathrm{P}_{\mathrm{a}} \mathrm{O}_{2}$ during $\mathrm{CPB}$ was $220 \mathrm{mmHg}(213-233)$ versus $157(152-161)(P<0.0001)$ in the conservative group. The lowest haemoglobin concentration during $\mathrm{CPB}$ was $92 \mathrm{~g} / \mathrm{L}$ (87-97) vs. 89 (84-95) $(P=0.170)$. During aortic cross-clamping, weighted $\mathrm{P}_{\mathrm{a}} \mathrm{O}_{2}$ was $214 \mathrm{mmHg}(207-224)$ vs. 146 (141-151) $(P<0.0001)$. During ICU admission, weighted $\mathrm{P}_{\mathrm{a}} \mathrm{O}_{2}$ was $107 \mathrm{mmHg}(88-140)$ vs. $90 \quad(85-97)(P=0.034)$, respectively. Haemoglobin concentrations were $119 \mathrm{~g} / \mathrm{L}(111-126)$ vs. $119(113-122)(P=0.690)$ on ICU admission. Patients in the control group were on mechanical ventilation for $4.1 \mathrm{~h}(3.2-5.0)$ with an $\mathrm{F}_{\mathrm{I}} \mathrm{O}_{2}$ of $0.52(0.43-0.60)$. Patients in the conservative group were on mechanical ventilation for $4.3 \mathrm{~h}(3.1-6.2)(P=0.383)$ with an $\mathrm{F}_{\mathrm{I}} \mathrm{O}_{2}$ of $0.38(0.32-0.44)(P<0.0001)$.

\section{Post-operative course}

Three patients underwent a re-thoracotomy for postoperative bleeding (one in the control group vs. two in the conservative group). One patient in the conservative group then developed cardiogenic shock (lowest $\mathrm{P}_{\mathrm{a}} \mathrm{O}_{2}=$ $76 \mathrm{mmHg}$ ). Two patients (one in either group) were scheduled for percutaneous coronary intervention after full recovery due to incomplete revascularisation. One patient in the conservative group had a ST-segment elevation myocardial infarction (STEMI) during ICU admission that did not require additional treatment (CK$\mathrm{MB}_{\max }=74.9 \mu \mathrm{g} / \mathrm{L}$ ). None of these events led to prolonged ICU admission. Patients in the control group were admitted to the ICU for $22 \mathrm{~h}$ (19-24) versus $22.5 \mathrm{~h}$ (19.5$24.5)$ for patients in the conservative group $(P=1.000)$.
Table 1 Baseline and surgical characteristics

\begin{tabular}{|c|c|c|}
\hline & $\begin{array}{l}\text { Hyperoxia } \\
\mathrm{n}=25\end{array}$ & $\begin{array}{l}\text { Normoxia } \\
\mathrm{n}=25\end{array}$ \\
\hline \multicolumn{3}{|l|}{ Demographics } \\
\hline Age, years & $66(61-71)$ & $68(66-71)$ \\
\hline Male, n (\%) & $25(100)$ & $25(100)$ \\
\hline Body surface area, $\mathrm{m}^{2}$ & $2.1(1.9-2.1)$ & $2.1(1.9-2.0)$ \\
\hline Caucasian race, n (\%) & $25(100)$ & $25(100)$ \\
\hline \multicolumn{3}{|l|}{ Medical history } \\
\hline Smoker, n (\%) & $16(64)$ & $17(68)$ \\
\hline Diabetes, n (\%) & $6(24)$ & $5(20)$ \\
\hline Hypertension, n (\%) & $7(28)$ & $13(52)$ \\
\hline $\begin{array}{l}\text { Hypercholesterolaemia, } \\
\text { n (\%) }\end{array}$ & $5(25)$ & $8(32)$ \\
\hline Renal insufficiency, n (\%) & $1(4)$ & $5(20)$ \\
\hline Cardiac arrest, n (\%) & $1(4)$ & $1(4)$ \\
\hline $\begin{array}{l}\text { Cerebrovascular accident, } \\
\text { n (\%) }\end{array}$ & $1(4)$ & $2(8)$ \\
\hline \multicolumn{3}{|l|}{ Cardiovascular history } \\
\hline Atrial fibrillation, n (\%) & $3(12)$ & $2(8)$ \\
\hline Myocardial infarction, n (\%) & $14(56)$ & $8(32)$ \\
\hline $\mathrm{PCl}, \mathrm{n}(\%)$ & $6(24)$ & $6(24)$ \\
\hline \multicolumn{3}{|l|}{ Left ventricular function } \\
\hline Good, n (\%) & $19(76)$ & $17(68)$ \\
\hline Moderate, n (\%) & $5(20)$ & $6(24)$ \\
\hline Poor, n (\%) & $1(4)$ & $2(8)$ \\
\hline \multicolumn{3}{|l|}{ Baseline laboratory parameters } \\
\hline Troponin-T ( $\mu \mathrm{g} / \mathrm{L})$ & $0.012(0.009-0.016)$ & $0.014(0.009-0.031)$ \\
\hline CK (U/L) & $86(57-126)$ & $77(56-102)$ \\
\hline CK-MB ( $\mu \mathrm{g} / \mathrm{L})$ & $0(0-1.9)$ & $0(0-0)$ \\
\hline Serum creatinine (mmol/L) & $78(69-93)$ & $88(74-108)$ \\
\hline Haemoglobin (g/L) & $142(139-148)$ & $140(132-148)$ \\
\hline \multicolumn{3}{|l|}{ Surgical characteristics } \\
\hline Number of grafts, $n$ & $4(3-4)$ & $4(4-5)$ \\
\hline Surgery time, min & $240(212-283)$ & $245(220-280)$ \\
\hline CPB time, $\min$ & $103(85-122)$ & $103(95-133)$ \\
\hline Cross clamp time, min & $66(56-80)$ & $69(60-85)$ \\
\hline Blood cardioplegia, n (\%) & $2(8)$ & $6(24)$ \\
\hline
\end{tabular}

Data are presented as median (interquartile range) unless otherwise stated. Renal insufficiency was defined as an estimated glomerular filtration rate $<60 \mathrm{~mL} / \mathrm{min}$. CK creatine kinase, CPB cardiopulmonary bypass, $M B$ muscle/ brain, $P C l$ percutaneous coronary intervention

\section{Myocardial damage}

CK-MB values generally peaked at $6 \mathrm{~h}$ after ICU admission (Fig. 1a). AUC were $23.5 \mu \mathrm{g} / \mathrm{L} / \mathrm{h}(18.4-28.1)$ in the control group vs. $21.5(15.8-26.6)(P=0.347)$ in the conservative group. Individual maximum values were $25.8 \mu \mathrm{g} / \mathrm{L}(21.0-32.3)$ vs. $24.9(18.4-31.5)(P=0.528)$. 

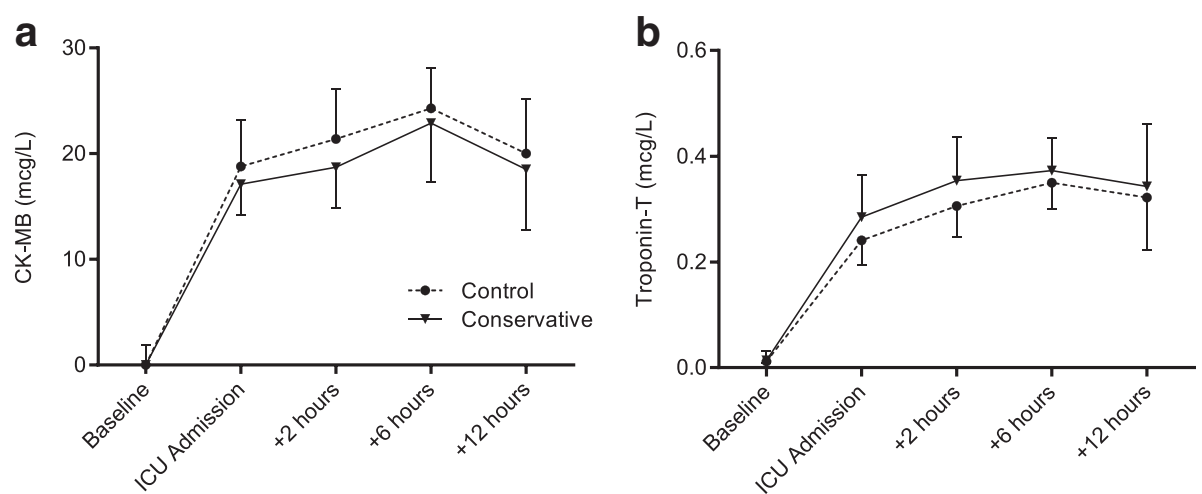

Fig. 1 Perioperative a CK-MB and $\mathbf{b}$ Troponin-T levels. There were no differences between groups. CK-MB creatine kinase-muscle/brain, ICU intensive care unit

Troponin-T levels rose substantially after surgery and usually peaked at $6 \mathrm{~h}$ after ICU admission (Fig. 1b). AUC were not different between groups $(0.30 \mu \mathrm{g} / \mathrm{L} / \mathrm{h}$ $(0.25-0.44)$ vs. $0.39(0.24-0.43) ; P=0.695))$. Individual peak values were $0.35 \mu \mathrm{g} / \mathrm{L}(0.30-0.46)$ vs. $0.42(0.26-0.49)$ $(P=0.923)$.

CK levels rose gradually during ICU stay and did not decline in the following 12-h study period. AUC were similar at $550 \mathrm{U} / \mathrm{L} / \mathrm{h}(347-706)$ vs. $376(229-425)(P=0.144)$. Individual maximum values measured were $663 \mathrm{U} / \mathrm{L}$ (403-977) vs. $511(329-637)(P=0.165)$.

To correct for an imbalance between groups in the number of patients who received warm blood cardioplegia (Table $1 ; P=0.247$ ), we performed a multiple linear regression with CK-MB AUC as the dependent variable, and study group, minutes on $\mathrm{CPB}$ and type of cardioplegia as independent variables. Neither study group $(\beta=0.024, P=0.874)$, nor minutes on CPB $(\beta=0.200$, $P=0.178)$ nor type of cardioplegia $(\beta=-0.003, P=0.984)$ were associated with CK-MB AUC $\left(R^{2}=0.041\right)$.

\section{Tissue perfusion, organ function and injury}

Creatinine remained stable throughout the study period (Fig. 2a). Lactate levels increased mildly in both groups and were not different between groups (Fig. 2b). On ICU admission, lung injury scores were $1.3(0.8-1.5)$ in the control group vs. $1.0(0.7-1.5)(P=0.290)$ in the conservative group. Two days later, LIS was $1.0(0.8-1.5)$ vs. $1.0(0-1.5)$ $(P=0.216)$. During ICU admission, weighted $\mathrm{P}_{\mathrm{a}} \mathrm{O}_{2} / \mathrm{F}_{\mathrm{I}} \mathrm{O}_{2}$ ratios were $236(173-285)$ vs. $261(199-311)(P=0.244)$.

\section{Haemodynamics}

In 15 patients in the control group a pulmonary artery catheter was inserted. Preoperatively, 11 had good Left Ventricular Function (LVF), 3 moderate and 1 poor. In the conservative group, 18 patients received a pulmonary artery catheter, with 10 having good LVF, 6 moderate and 2 poor.
Before sternotomy, CI was similar between groups $\left(1.9 \mathrm{~L} / \mathrm{min} / \mathrm{m}^{2}(1.6-2.1)\right.$ vs. $\left.1.9(1.6-2.2) ; P=1.000\right)$. After chest closure, $\mathrm{CI}$ was increased compared to baseline in both groups $(2.6(2.2-3.2)$ vs. $2.8(2.4-3.0))$. After admission to the ICU, CI decreased slightly and then remained stable throughout the next 12 hours (Fig. 3a). There was no difference between the two groups at any point. SVRI rose gradually in both groups (Fig. 3b), starting at 2120 dynes $\cdot \mathrm{s} / \mathrm{cm}^{5} / \mathrm{m}^{2}(1711-2254)$ in the control group and $1970(1787-2311)$ in the conservative group and reaching a maximum at $12 \mathrm{~h}$ of ICU admission (2955 (2398-3351) vs. 2883 (2564-3161); $P=0.861)$.

Nearly all patients in either group were supported with a low dose of dopamine in the first hours after ICU admission (22/25 in the control group vs. 20/25 in the conservative group). Overall administration of vasoactive medicine was not different between groups (data not shown).

\section{Oxidative stress}

At baseline, there was no difference in F2-isoprostane levels between groups $(32.1 \mathrm{ng} / \mathrm{L}(26.7-36.0)$ in the control group vs. $34.3(24.8-43.2)$ in the conservative group; $P=0.467$ ). Six hours after ICU admission, F2isoprostane levels were lower in both groups compared to baseline $(P<0.001)$, but there was no difference between groups (25.9 ng/L (23.7-28.5) vs. 27.3 (22.6-31.6); $P=0.399$ ).

ROS production by PMN increased in the control group from a mean 21.3 MFI (95\% confidence interval $14.6-28)$ at baseline to $45.9(21.8-70.0)(P=0.001)$ at $1 \mathrm{~h}$ of CPB. In the conservative group, ROS production increased similarly from 15.6 MFI (10.1-20.7) at baseline to $45.2(14.5-76.0)(P=0.002)$ during CPB. There was no difference between groups either at baseline $(P=0.228)$ or at $1 \mathrm{~h}$ of $\mathrm{CPB}(P=0.790)$. 


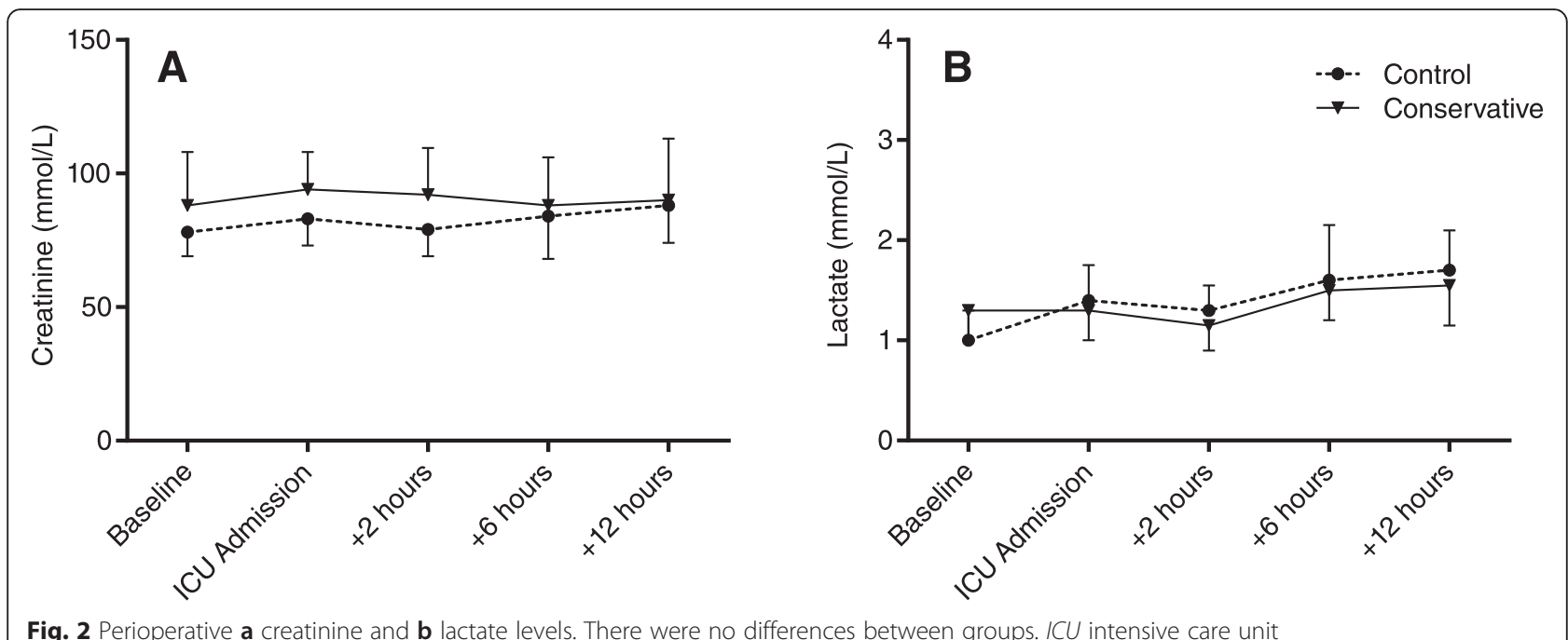

Fig. 2 Perioperative $\mathbf{a}$ creatinine and $\mathbf{b}$ lactate levels. There were no differences between groups. ICU intensive care unit

\section{Safety outcome}

All patients that participated in the study survived until hospital discharge. There were no hypoxic events $\left(\mathrm{P}_{\mathrm{a}} \mathrm{O}_{2}<55 \mathrm{mmHg}\right)$ in either study group.

\section{Discussion}

In the present RCT in patients undergoing scheduled isolated CABG surgery, we found no difference in markers of myocardial damage between a conventional moderate hyperoxic and a near-physiological oxygen strategy during and after surgery. The conservative oxygenation strategy did not improve haemodynamics in comparison to moderate hyperoxia. However, lower oxygen targets during $\mathrm{CPB}$ and ICU admission could be applied safely without risk of hypoxia.
With respect to myocardial damage, these findings are in apparent contrast to results from earlier clinical trials where the reduction of oxygen tension during $\mathrm{CPB}$ or reperfusion resulted in lower CK (672 \pm 130 vs. $293 \pm 21 \mathrm{U} / \mathrm{l} ; P=0.002)$ [1] or lower Troponin-T levels $(\sim 2.1$ vs. $\sim 0.8 \mu \mathrm{g} / \mathrm{L} ; P<0.05)$ [2]. However, the high $\mathrm{P}_{\mathrm{a}} \mathrm{O}_{2}$ investigated in the latter two studies are no longer applied today. The first study compared a $\mathrm{P}_{\mathrm{a}} \mathrm{O}_{2}$ of $\sim 400 \mathrm{mmHg}$ during $\mathrm{CPB}$ in the control group to $\sim 140 \mathrm{mmHg}$ in the conservative group [2]. The second study compared reperfusion oxygen tensions of $450-550 \mathrm{mmHg}$ to 200-250 mmHg [1]. This means that, in the conservative group, oxygen tension was reduced by $260-270 \mathrm{mmHg}$ compared to the control group. In our study, the difference was on average $70 \mathrm{mmHg}$ during $\mathrm{CPB}$ and $20 \mathrm{mmHg}$ during ICU admission. It is reasonable to assume that a

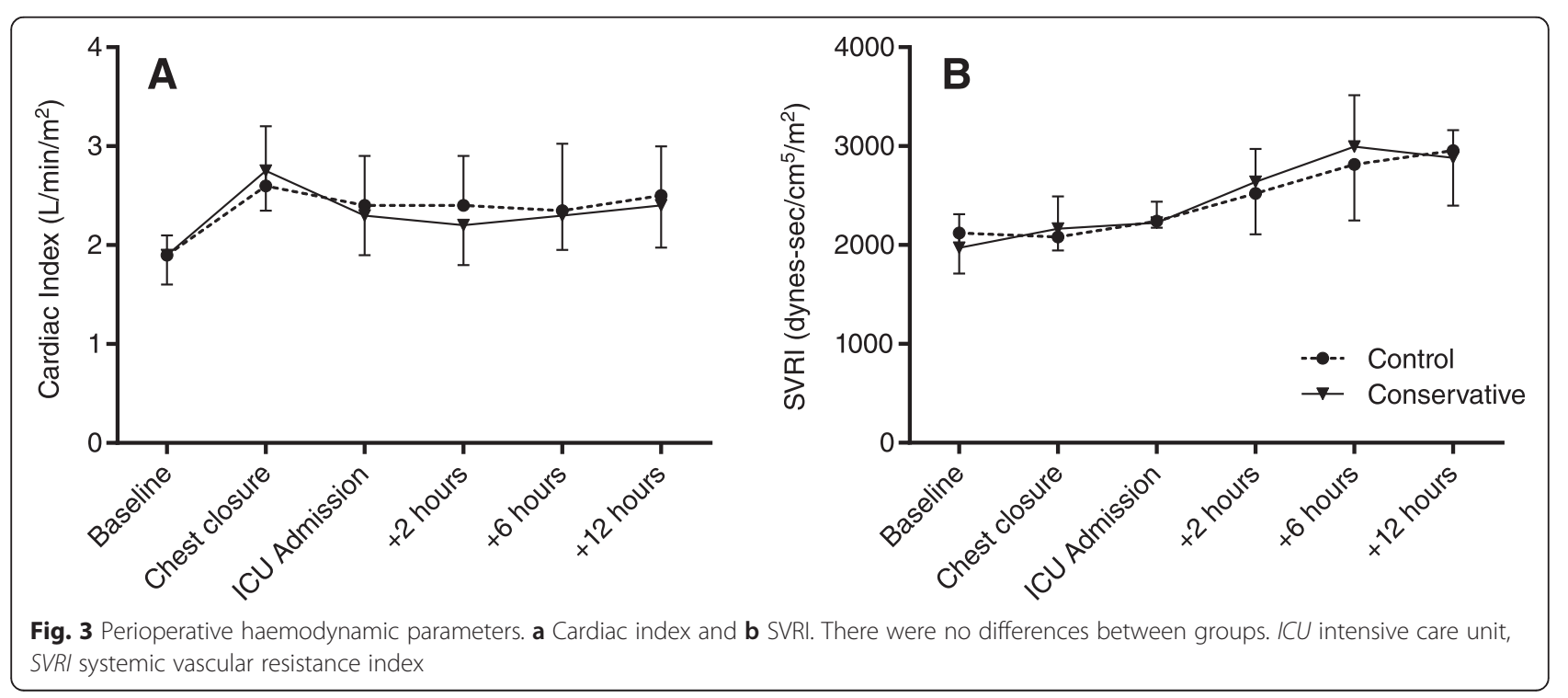


smaller reduction in oxygen tension has a smaller effect on myocardial damage.

Our results are in contrast to those of the AVOID trial, which compared the effect of $8 \mathrm{~L} / \mathrm{min}$ oxygen vs. no-oxygen supplementation in non-hypoxic patients with STEMI. The study showed increased CK, a trend for increased Troponin-I and increased infarction size when patients received supplemental oxygen [28]. Unfortunately, the study was oxygen saturation-guided and there are no $\mathrm{P}_{\mathrm{a}} \mathrm{O}_{2}$ values available, so we cannot deduce whether oxygen tensions were in the same range. Of course, an obvious difference between the patient populations is that, in STEMI, the insult is acute, while in CABG surgery the patient is prepared with moderate hypothermia and cardioplegia. This fundamental physiological difference may explain the contrasting results.

In addition, an important difference with previous CABG studies is that our patients received $1 \mathrm{mg} / \mathrm{kg}$ dexamethasone after anaesthesia induction [31]. Dexamethasone is a potent glucocorticoid that reduces the formation of ROS by leukocytes in vivo [32] and, in CABG surgery, reduces the systemic inflammatory response syndrome [33, 34]. Since it is hypothesised that hyperoxia exerts its effects by augmenting production of ROS, it is possible that dexamethasone mitigates these effects. In anaesthetised [26, 33] and septic patients [34] supplemental oxygen can decrease CI and increase SVRI [14]. In these studies the contrast between the normoxic and hyperoxic state was high (i.e. switching from an $\mathrm{F}_{\mathrm{I}} \mathrm{O}_{2}$ of $\sim 0.3$ to 1.0$)$ and short term (10-30 min). In our study, moderate hyperoxia appears to have no effect on CI or SVRI. Although the relatively lower $\mathrm{P}_{\mathrm{a}} \mathrm{O}_{2}$ difference between groups post-operatively may have led to a minor and immeasurable difference in haemodynamic parameters, it is also possible that the haemodynamic effects are only temporary. Also, dexamethasone influences vascular endothelial and smooth muscle $\mathrm{Ca}^{2+}$ mobilisation [35], which in turn modulates the balance between vasoconstriction and vasodilation which may have affected the vascular response to oxygen.

Over the years, CABG surgery has improved and the influence of oxygen tension may be less in current highquality surgery and post-operative care. This view is supported by observation that cardiac markers in the present study appear lower than in earlier studies. For instance, the lowest maximal Troponin- $\mathrm{T}$ reported in one study was $\sim 0.8 \mathrm{ng} / \mathrm{mL}$ and the lowest maximal CK$\mathrm{MB} \sim 50 \mathrm{ng} / \mathrm{mL}$ [2]. In our study, we found levels that were approximately $50 \%$ lower $(0.42 \mathrm{ng} / \mathrm{mL}$ for Troponin-T and $24.9 \mathrm{ng} / \mathrm{mL}$ for CK-MB). It should be noted, however, that the actual difference may be slightly different, since the assays to detect these markers have changed as well. However, in the case of Troponin- $\mathrm{T}$, all commercial assays have been using the same set of antibodies for years and comparability between assay generations is good in the upper range [36, 37].

The present study shows that employing a strategy with lower oxygenation targets can be performed safely in low-risk CABG surgery. There were no hypoxic events and there was no increase in lactate or creatinine levels, indicating adequate aerobic metabolism. This finding is in agreement with another study that focussed solely on strategies to avoid hyperoxia during CPB [3]. Only one other (retrospective) study reported postoperative creatinine levels, and, like our results, they did not find a difference between the control and conservative group [38].

\section{Study limitations}

Although we anticipated that the current intervention would possibly find a smaller effect on cardiac markers compared to earlier trials $[1,2]$, we did not foresee the overall lower levels of Troponin-T and CK-MB. A revised power calculation with the present numbers indicates that 51 patients in either arm would be needed to detect a CK-MB difference of $20 \%$ with $80 \%$ power. However, amending the protocol to increase the sample size was deemed futile. If the sample size was to be doubled, the conditional power to detect the hypothesised effect (20\% difference in CK-MB) was $46 \%$. Assuming that the current trend continued, the conditional power would be only $11 \%$.

The $\mathrm{P}_{\mathrm{a}} \mathrm{O}_{2}$ of some patients in the control group were lower than the desired targets. Due to the toxicity of oxygen for lung tissue, we found it unethical and not compatible with daily practice to increase $\mathrm{F}_{\mathrm{I}} \mathrm{O}_{2}$ above 0.60 for study purposes only. In these cases, we accepted adequate, but lower than target, $\mathrm{P}_{\mathrm{a}} \mathrm{O}_{2}$. Although we think that it may have reduced differences between groups, it is unlikely that it entirely explains our results. For one, in previous studies $\mathrm{P}_{\mathrm{a}} \mathrm{O}_{2}$ was controlled during surgery only, suggesting that in CABG surgery intraoperative oxygenation has the more profound impact on myocardial damage $[1,2]$. Secondly, weighted $\mathrm{P}_{\mathrm{a}} \mathrm{O}_{2}$ was different between groups during ICU admission and therefore differential oxygen exposure was longer in our trial than in previous ones.

Despite randomisation, slightly more patients in the conservative group received warm blood cardioplegia as opposed to crystalloid cardioplegia. We do not think that this small imbalance had severe effects on the results of this trial. Although the literature is far from conclusive, warm blood cardioplegia appears to be related to a small reduction of CK-MB release after surgery [39]. At best, this could have led to a false positive-that a reduction of oxygen tension reduces cardiac damage. In addition, we did not find an association between type of 
cardioplegia and CK-MB AUC using multiple linear regression.

All patients endured at least three short episodes of hyperoxia: 1) during pre-oxygenation; 2) during simultaneous oxygenation through the endotracheal tube and the extracorporeal oxygenator; and 3) during transport from the OR to the ICU. That these short periods of hyperoxia explain our results seems unlikely, but cannot be ruled out either.

The current study was performed in a low-risk CABG population. The same intervention in high-risk patients or during combined surgery (CABG + valvular surgery) may give different results.

To reduce the impact of CPB haemodilution on oxygenation, we included patients with a minimum body size and pre-operative haemoglobin level. Patients that are more affected by the volume of the $\mathrm{CPB}$ circuit (i.e. smaller or anaemic patients) might respond differently to either of the two oxygen strategies. Additionally, due to these criteria (especially body surface index) nearly all eligible participants were male, which makes the results of this trial gender specific.

\section{Clinical implications and future directions}

The most important note from this trial for clinical perfusionists and physicians is that lower arterial oxygen targets can be applied safely during $\mathrm{CPB}$ and postoperative intensive care. These results are in accordance with several recently published implementation studies for conservative oxygen therapy in the ICU [40-42].

With regard to the effects of hyperoxia on the cardiovascular system, it seems that perfusionists and physicians do not have to be particularly concerned about possible oxygen-induced haemodynamic disturbances in uncomplicated post-CABG patients, at least in the range of $80-150 \mathrm{mmHg}$.

Now that it is becoming clearer that aiming for lower arterial oxygen tensions is not harmful, we feel it is time for much larger RCTs in order to find optimal oxygenation targets in high-risk and combined cardiac surgery and intensive care. With this thought, we have initiated a multicentre RCT (O2-ICU, NCT02321072) to investigate optimal oxygenation targets in the ICU.

\section{Conclusion}

In the present RCT in elective isolated CABG surgery and post-operative intensive care, an oxygenation strategy towards near-physiological arterial oxygen tensions did not result in less myocardial damage or improved haemodynamics in comparison to moderate hyperoxia. However, the conservative oxygen strategy was safe and can be employed without concern for inadequate aerobic metabolism. Future, much larger RCTs are required to determine optimal oxygenation targets in high-risk and combined cardiac surgery and intensive care.

\section{Key messages}

- A near-physiological $\mathrm{P}_{\mathrm{a}} \mathrm{O}_{2}$ oxygenation strategy during and after CABG surgery did not result in less myocardial damage, compared to moderate hyperoxia

- In elective isolated CABG surgery, a conservative oxygen strategy does not improve haemodynamics, compared to moderate hyperoxia

- A conservative oxygen strategy can be applied safely both during CPB and ICU admission without hypoxic events

\section{Additional files}

Additional file 1: Cardiopulmonary bypass details. A more detailed description of the cardiopulmonary bypass used during the study. (DOCX $12 \mathrm{~kb}$ )

Additional file 2: Oxidative stress method details. A more detailed description of the methods used to measure F2-isoprostanes and reactive oxygen species production by polymorphonuclear cells during the study. (DOCX $14 \mathrm{~kb}$ )

Additional file 3: CONSORT 2010 flow diagram. Diagram of the inclusion and exclusion of study subjects according to the CONSORT 2010 statement. (DOC 47 kb)

\begin{abstract}
Abbreviations
AUC: Area under the curve; CABG: Coronary artery bypass graft; $\mathrm{Cl}$ : Cardiac index; CK: Creatinine kinase; CPB: Cardiopulmonary bypass; $\mathrm{F}_{1} \mathrm{O}_{2}$ : Fraction of inspired oxygen; ICU: Intensive care unit; IQR: Interquartile range;

ITT: Intention-to-treat; LIS: Lung injury score; LVF: Left ventricular function; MB: Creatinine kinase - muscle/brain; MFI: Mean fluorescence intensity; OR: Operating room; $\mathrm{P}_{\mathrm{a}} \mathrm{O}_{2}$ : Partial pressure of oxygen in arterial blood; PMN: Polymorphonuclear leukocytes; RCT: Randomised controlled trial; ROS: Reactive oxygen species; STEMI: ST-segment elevation myocardial infarction; SVRI: Systemic vascular resistance index.
\end{abstract}

\section{Competing interests}

The authors declare that they have no competing interests.

\section{Authors' contributions}

BS recruited patients, collected blood samples, carried out the flow cytometry assays, analysed data and drafted the manuscript. YMS conceived and participated in the design of the study and helped to draft the manuscript. MCdW helped to interpret the data and revised the manuscript. CB helped with acquisition of data and revised the manuscript. ABAV helped with acquisition of data, performed CABG surgery on participants and revised the manuscript. DV helped with acquisition of data, was responsible for cardiopulmonary bypass during surgery and revised the manuscript. SK helped with acquisition of data, was responsible for clinical management and anaesthesia during surgery and revised the manuscript. HJSdG performed the statistical analysis and revised the manuscript. JJGV helped with acquisition of data, with the design of the flow cytometry assay and revised the manuscript. RJPM helped with acquisition of data, with the design of the flow cytometry assay and revised the manuscript. ARJG helped with acquisition of data, was responsible for clinical management after surgery and revised the manuscript. HMOvS participated in the design of the study, was responsible for clinical management after surgery and helped to draft the manuscript. AMESdM conceived the study, was responsible for clinical management after surgery, participated in its design and co- 
ordination and helped to draft the manuscript. All authors read and approved the final manuscript.

\section{Acknowledgements}

This investigation was supported by grants from ESICM NEXT Start-Up 2014 and The Netherlands Organisation for Health Research and Development project 836031007 .

\begin{abstract}
Author details
'Department of Intensive Care, VU University Medical Center, Amsterdam, The Netherlands. ${ }^{2}$ Department of Internal Medicine, VU University Medical Center, Amsterdam, The Netherlands. ${ }^{3}$ Department of Anaesthesiology, VU University Medical Center, Amsterdam, The Netherlands. ${ }^{4}$ Department of Cardiothoracic Surgery, VU University Medical Center, Amsterdam, The Netherlands. ${ }^{5}$ Department of Molecular Cell Biology \& Immunology, VU University Medical Center, Amsterdam, The Netherlands. ${ }^{6}$ Department of Physiology, VU University Medical Center, Amsterdam, The Netherlands.
\end{abstract}

\section{Received: 2 November 2015 Accepted: 10 February 2016} Published online: 10 March 2016

\section{References}

1. Ihnken K, Winkler A, Schlensak C, Sarai K, Neidhart G, Unkelbach U, et al. Normoxic cardiopulmonary bypass reduces oxidative myocardial damage and nitric oxide during cardiac operations in the adult. J Thorac Cardiovasc Surg. 1998;116:327-34.

2. Inoue T, Ku K, Kaneda T, Zang Z, Otaki M, Oku H. Cardioprotective effects of lowering oxygen tension after aortic unclamping on cardiopulmonary bypass during coronary artery bypass grafting. Circ J. 2002;66:718-22.

3. Toraman F, Evrenkaya S, Senay S, Karabulut H, Alhan C. Adjusting oxygen fraction to avoid hyperoxemia during cardiopulmonary bypass. Asian Cardiovasc Thorac Ann. 2007;15:303-6.

4. Karu I, Tähepõld P, Ruusalepp A, Zilmer K, Zilmer M, Starkopf J. Effects of 60 minutes of hyperoxia followed by normoxia before coronary artery bypass grafting on the inflammatory response profile and myocardial injury. J Negat Results Biomed. 2012:11:14

5. Karu I, Loit R, Zilmer K, Kairane C, Paapstel A, Zilmer M, et al. Pre-treatment with hyperoxia before coronary artery bypass grafting-effects on myocardial injury and inflammatory response. Acta Anaesthesiol Scand. 2007;51:1305-13.

6. Joachimsson PO, Sjöberg F, Forsman M, Johansson M, Ahn HC, Rutberg H. Adverse effects of hyperoxemia during cardiopulmonary bypass. J Thorac Cardiovasc Surg. 1996;112:812-9.

7. de Jonge $E$, Peelen L, Keijzers PJ, Joore $H$, de Lange $D$, van der Voort PHJ, et al. Association between administered oxygen, arterial partial oxygen pressure and mortality in mechanically ventilated intensive care unit patients. Crit Care. 2008;12:R156.

8. Suzuki S, Eastwood GM, Peck L, Glassford NJ, Bellomo R. Current oxygen management in mechanically ventilated patients: a prospective observational cohort study. J Crit Care. 2013;28:647-54.

9. Brower RG, Lanken PN, Maclntyre N, Matthay MA, Morris A, Ancukiewicz M, et al. Higher versus lower positive end-expiratory pressures in patients with the acute respiratory distress syndrome. N Engl J Med. 2004;351:327-36.

10. Sjöberg F, Singer M. The medical use of oxygen: a time for critical reappraisal. J Intern Med. 2013:274:505-28.

11. Cornet AD, Kooter AJ, Peters MJ, Smulders YM. The potential harm of oxygen therapy in medical emergencies. Crit Care. 2013;17:313.

12. Pries AR, Heide J, Ley K, Klotz KF, Gaehtgens P. Effect of oxygen tension on regulation of arteriolar diameter in skeletal muscle in situ. Microvasc Res. 1995:49:289-99.

13. Cabrales $P$, Tsai AG, Intaglietta M. Nitric oxide regulation of microvascular oxygen exchange during hypoxia and hyperoxia. J Appl Physiol. 2006;100:1181-7.

14. Frisbee JC, Lombard JH. Elevated oxygen tension inhibits flow-induced dilation of skeletal muscle arterioles. Microvasc Res. 1999;58:99-107.

15. Gao Z, Spilk S, Momen A, Muller MD, Leuenberger UA, Sinoway LI. Vitamin $C$ prevents hyperoxia-mediated coronary vasoconstriction and impairment of myocardial function in healthy subjects. Eur J Appl Physiol. 2012; 112(2 PG - 483-492):483-92.
16. Orbegozo Cortés D, Puflea F, Donadello K, Taccone FS, Gottin L, Creteur J, et al. Normobaric hyperoxia alters the microcirculation in healthy volunteers. Microvasc Res. 2015;98(PG - 23-28):23-8.

17. Bak Z, Sjoberg F, Rousseau A, Steinvall I, Janerot-Sjoberg B, Sjöberg F, et al. Human cardiovascular dose-response to supplemental oxygen. Acta Physiol. 2007:191:15-24.

18. Mak S, Egri Z, Tanna G, Colman R, Newton GE. Vitamin C prevents hyperoxia-mediated vasoconstriction and impairment of endotheliumdependent vasodilation. Am J Physiol Heart Circ Physiol. 2002;282:H2414-21.

19. McNulty PH, Robertson BJ, Tulli MA, Hess J, Harach LA, Scott S, et al. Effect of hyperoxia and vitamin C on coronary blood flow in patients with ischemic heart disease. J Appl Physiol. 2007;102(5 PG - 2040-5):2040-5.

20. Rubanyi GM, Vanhoutte PM. Superoxide anions and hyperoxia inactivate endothelium-derived relaxing factor. Am J Physiol. 1986;250(5 Pt 2):H822-7.

21. Mouren S, Souktani R, Beaussier M, Abdenour L, Arthaud M, Duvelleroy M, et al. Mechanisms of coronary vasoconstriction induced by high arterial oxygen tension. Am J Physiol. 1997:272(1 Pt 2):H67-75.

22. Wang $\mathrm{C}-\mathrm{H}$, Chang $\mathrm{W}-\mathrm{T}$, Huang $\mathrm{C}-\mathrm{H}$, Tsai M-S, Yu P-H, Wang A-Y, et al. The effect of hyperoxia on survival following adult cardiac arrest: a systematic review and meta-analysis of observational studies. Resuscitation. 2014;85:1142-8

23. Pilcher J, Weatherall M, Shirtcliffe P, Bellomo R, Young P, Beasley R. The effect of hyperoxia following cardiac arrest-a systematic review and metaanalysis of animal trials. Resuscitation. 2012;83:417-22.

24. Janz DR, Hollenbeck RD, Pollock JS, McPherson JA, Rice TW. Hyperoxia is associated with increased mortality in patients treated with mild therapeutic hypothermia after sudden cardiac arrest. Crit Care Med. 2012;40:3135-9.

25. Couper $\mathrm{K}$, Yeung J. Hyperoxia following cardiac arrest: how much is too much? Resuscitation. 2014;85:1123-4.

26. Bellomo R, Bailey M, Eastwood GM, Nichol A, Pilcher D, Hart GK, et al. Arterial hyperoxia and in-hospital mortality after resuscitation from cardiac arrest. Crit Care. 2011;15:R90.

27. Rønning OM, Guldvog B. Should stroke victims routinely receive supplemental oxygen? A quasi-randomized controlled trial. Stroke. 1999:30:2033-7.

28. Stub D, Smith K, Bernard S, Nehme Z, Stephenson M, Bray JE, et al. Air versus oxygen in ST-segment elevation myocardial infarction. Circulation. 2015;131:2143-50

29. Harten JM, Anderson KJ, Kinsella J, Higgins MJ. Normobaric hyperoxia reduces cardiac index in patients after coronary artery bypass surgery. J Cardiothorac Vasc Anesth. 2005:19:173-5.

30. Murray JF, Matthay MA, Luce JM, Flick MR. An expanded definition of the adult respiratory distress syndrome. Am Rev Respir Dis. 1988;138:720-3.

31. Dieleman JM, Nierich AP, Rosseel PM, van der Maaten JM, Hofland J, Diephuis JC, et al. Intraoperative high-dose dexamethasone for cardiac surgery: a randomized controlled trial. JAMA. 2012;308:1761-7.

32. Dandona P, Mohanty P, Hamouda W, Aljada A, Kumbkarni Y, Garg R. Effec of dexamethasone on reactive oxygen species generation by leukocytes and plasma interleukin-10 concentrations: a pharmacodynamic study. Clin Pharmacol Ther. 1999:66:58-65.

33. Cappabianca G, Rotunno C, de Luca Tupputi Schinosa L, Ranieri VM, Paparella D. Protective effects of steroids in cardiac surgery: a metaanalysis of randomized double-blind trials. J Cardiothorac Vasc Anesth. 2011;25:156-65.

34. El Azab SR, Rosseel PMJ, de Lange JJ, Groeneveld ABJ, van Strik R, van Wijk $\mathrm{EM}$, et al. Dexamethasone decreases the pro- to anti-inflammatory cytokine ratio during cardiac surgery. Br J Anaesth. 2002;88:496-501.

35. Rogers KM, Bonar CA, Estrella JL, Yang S. Inhibitory effect of glucocorticoid on coronary artery endothelial function. Am J Physiol Heart Circ Physiol. 2002;283:H1922-8

36. Hermsen D, Apple F, Garcia-Beltràn L, Jaffe A, Karon B, Lewandrowski E, et al. Results from a multicenter evaluation of the 4th generation Elecsys Troponin T assay. Clin Lab. 2007:53:1-9.

37. Saenger AK, Beyrau R, Braun S, Cooray R, Dolci A, Freidank H, et al. Multicenter analytical evaluation of a high-sensitivity troponin $\mathrm{T}$ assay. Clin Chim Acta. 2011;412:748-54

38. Brown DM, Holt DW, Edwards JT, Burnett RJ. Normoxia vs. hyperoxia: impact of oxygen tension strategies on outcomes for patients receiving cardiopulmonary bypass for routine cardiac surgical repair. J Extra Corpor Technol. 2006;38:241-8.

39. Jacob S, Kallikourdis A, Sellke F, Dunning J. Is blood cardioplegia superior to crystalloid cardioplegia? Interact Cardiovasc Thorac Surg. 2008;7:491-8. 
40. Helmerhorst HJF, Schultz MJ, van der Voort PHJ, Bosman RJ, Juffermans NP, de Wilde RBP, et al. Effectiveness and Clinical Outcomes of a Two-Step Implementation of Conservative Oxygenation Targets in Critically III Patients: A Before and After Trial. Crit Care Med. 2016:44:554-63.

41. Panwar R, Hardie M, Bellomo R, Barrot L, Eastwood GM, Young PJ, et al. Conservative versus liberal oxygenation targets for mechanically ventilated patients. a pilot multicenter randomized controlled trial. Am J Respir Crit Care Med. 2016;193:43-51.

42. Suzuki S, Eastwood GM, Goodwin MD, Noë GD, Smith PE, Glassford N, et al. Atelectasis and mechanical ventilation mode during conservative oxygen therapy: a before-and-after study. J Crit Care. 2015;30:1232-7.

Submit your next manuscript to BioMed Central and we will help you at every step:

- We accept pre-submission inquiries

- Our selector tool helps you to find the most relevant journal

- We provide round the clock customer support

- Convenient online submission

- Thorough peer review

- Inclusion in PubMed and all major indexing services

- Maximum visibility for your research

Submit your manuscript at www.biomedcentral.com/submit
Biomed Central 